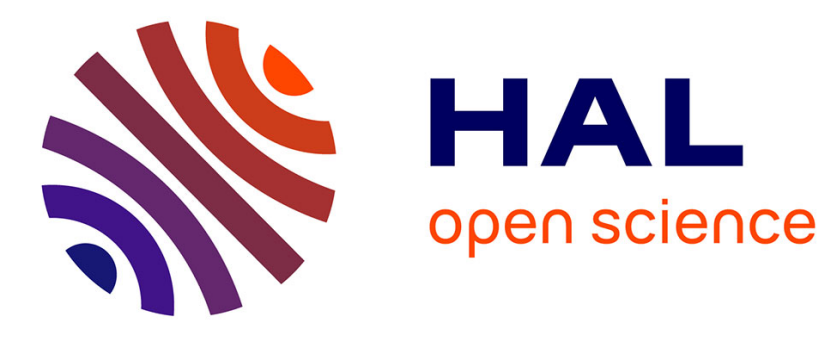

\title{
Engine Cooling System Optimization for Fuel Consumption Reduction
}

\author{
Jef Philippine, Alice Guille Des Buttes, Bruno Jeanneret, Rochdi Trigui, \\ Florian Deneve, Florian Pereyron
}

\section{- To cite this version:}

Jef Philippine, Alice Guille Des Buttes, Bruno Jeanneret, Rochdi Trigui, Florian Deneve, et al.. Engine Cooling System Optimization for Fuel Consumption Reduction. 2019 IEEE Vehicle Power and Propulsion Conference (VPPC), Oct 2019, Hanoi, France. 6p, 10.1109/VPPC46532.2019.8952496 . hal-02491671

\section{HAL Id: hal-02491671 \\ https://hal.science/hal-02491671}

Submitted on 26 Feb 2020

HAL is a multi-disciplinary open access archive for the deposit and dissemination of scientific research documents, whether they are published or not. The documents may come from teaching and research institutions in France or abroad, or from public or private research centers.
L'archive ouverte pluridisciplinaire HAL, est destinée au dépôt et à la diffusion de documents scientifiques de niveau recherche, publiés ou non, émanant des établissements d'enseignement et de recherche français ou étrangers, des laboratoires publics ou privés. 


\title{
Engine Cooling System Optimization for Fuel Consumption Reduction
}

\author{
Jef Philippine*, Alice Guille Des Buttes*, Bruno Jeanneret*, Rochdi Trigui*, \\ Florian Denève $^{\dagger}$ and Florian Pereyron ${ }^{\dagger}$ \\ *Univ Lyon, IFSTTAR, AME, ECO7, F-69500 Bron, France \\ Corresponding author: jef.philippine@ ifsttar.fr \\ ${ }^{\dagger}$ Powertrain Strategic Development, Volvo Group, Saint-Priest, France
}

\begin{abstract}
This paper describes the optimization of a truck engine cooling system. Different models work together to make an estimation of fuel consumption and thermal behavior of the engine on a real-drive cycle. Dynamic programming is then used to provide an optimized solution to the engine thermal management in terms of actuators power and fuel consumption. Engine temperature effect on the fuel consumption is taken into account by modeling the mechanical losses due to oil viscosity.
\end{abstract}

\section{INTRODUCTION}

In order to meet 2015 Paris Agreement targets on greenhouse gases emissions, transportation sector needs to deeply change and reduce its total energy consumption. Under the leading of Renault Trucks group, FALCON (Flexible \& Aerodynamic truck for Low CONsumption) project aims to develop a complete heavy-duty tractor-trailer combination that consumes $13 \%$ less fuel than a standard coupling towed by a Renault Trucks $\mathrm{T}$ vehicle. Within the project framework, the engine cooling system is studied in order to quantify potential fuel consumption savings by the use of better auxiliary actuators control.

In this work, vehicle model and fuel consumption model are first presented, based on IFSTTAR vehicle simulation library VEHLIB and a semi-trailer truck characteristics. VEHLIB is a Simulink library that integrates the necessary components model to develop and simulate conventional, hybrid or full-electric vehicles [1]. This set of models allows to obtain an accurate description of the engine thermal solicitation on a given driven cycle. It is then used in a thermal modeling of the engine cooling system. The control of actuators in this last model is then optimized using Dynamic Programming algorithm, and comparisons are made with a conventional configuration and control.

In order to evaluate the influence of oil temperature on engine friction losses and therefore on the overall fuel consumption, this paper proposes a model of fuel excess consumption due to engine oil viscosity and integrates it within the optimization framework.

\section{VEHICLE AND THERMAL MODELS}

\section{A. Vehicle model}

For optimization purposes, an inverse modeling approach of the vehicle is applied, as described in [2] or [3]. The goal

This work is financially supported by Renault Trucks Flexible \& Aerodynamic truck for Low CONsumption (FALCON) project. is to determine the necessary engine fuel consumption $\dot{m}_{f u e l}$ as a function of vehicle acceleration, specified vehicle speed $v, a$ and selected gear.

Only longitudinal forces are considered in this work, in order to determine the vehicle's longitudinal motion. Using Newton's second law, it can be written:

$$
J_{\text {veh }} \cdot \dot{\omega}_{\text {wheel }}=\Gamma_{\text {drive }}-F_{\text {res }} \cdot R_{\text {tire }}
$$

where $J_{v e h}$ is the vehicle's inertia to be accelerated, $\dot{\omega}_{w h e e l}$ is the rotational wheel acceleration, $\Gamma_{\text {drive }}$ is the drive train output torque generated by the vehicle's drive train, and $R_{\text {tire }}$ is the tire radius. $F_{r e s}$ are the resistance forces that depend on the vehicle speed and can be computed as the sum of rolling resistance, aerodynamic drag and road grade. No slipping between road and tire is considered in this energetic model. Inverting (1) leads to (2):

$$
\Gamma_{\text {drive }}=J_{\text {veh }} \cdot \frac{a}{R_{\text {tire }}}+F_{\text {res }}(v) \cdot R_{\text {tire }}
$$

Speed $\omega_{e n g}$ and torque $\Gamma_{\text {drive }_{e n g}}$ of the engine output shaft are calculated from the wheel rotational speed $\omega_{w h e e l}$, the engine idle speed, the drive train output torque $\Gamma_{\text {drive }}$ and the efficiencies and ratios of both gearbox and final drive reduction, respectively written $\eta_{G}, R_{G}, \eta_{F D}$ and $R_{F D}$. In particular, the engine output shaft torque is:

$$
\Gamma_{\text {drive }_{\text {eng }}}=\frac{\Gamma_{\text {drive }}}{\eta_{F D}^{\psi} \cdot R_{F D} \cdot \eta_{G}^{\psi} \cdot R_{G}}
$$

The parameter $\psi$ depends on the energy flow and is defined as:

$$
\psi=\operatorname{sign}\left(\Gamma_{\text {drive }}\right)
$$

The dynamics of the internal combustion engine can be described with:

$$
J_{e n g} \dot{\omega}_{e n g}=\Gamma_{e n g}-\Gamma_{\text {drive }_{e n g}}-\Gamma_{a u x}
$$

The load torque due to the auxiliaries $\Gamma_{a u x}$ is determined with $\omega_{\text {eng }} \cdot \Gamma_{a u x}=P_{a u x}$, where $P_{a u x}$ is the sum of non-cooling auxiliaries power (such as alternator power) and cooling auxiliaries (namely fan and pump) power, described in sections II-D and II-E. Inverting (5), the engine torque $\Gamma_{\text {eng }}$ can be computed as a function of wheel torque as:

$$
\Gamma_{\text {eng }}=\Gamma_{\text {drive }} \cdot \frac{\eta_{F D}^{\psi} \cdot \eta_{G}^{\psi}\left(i_{\text {gear }}\right)}{R_{F D} \cdot R_{G}\left(i_{\text {gear }}\right)}+\frac{P_{a u x}}{\omega_{e n g}}+J_{\text {eng }} \cdot \dot{\omega}_{\text {eng }}
$$




\section{B. Engine model}

In this work, the engine model proposed in [4] is used to evaluate the fuel mass flow rate $\dot{m}_{f u e l}$. The power delivered by the combustion $P_{\text {fuel }}$ can be written as:

$$
P_{\text {fuel }}=\dot{m}_{f u e l} \cdot L H V
$$

where $L H V$ is the lower heating value. Due to combustion efficiency, losses in cooling water and oil, losses in the exhaust gases and warming of the metallic parts of the engine, the gross indicated power $P_{i g}$ and the combustion power $P_{\text {fuel }}$ are not equal. They are linked through the fuel indicated efficiency $\eta_{f i}$ as:

$$
P_{i g}=\eta_{f i} \cdot P_{f u e l}
$$

The brake power $P_{b}$, is the usable power delivered by the engine, and is the result of the difference between the gross indicated power, $P_{i g}$, and the mechanical power losses in the engine $P_{f}$ :

$$
\begin{aligned}
P_{b} & =\omega_{e n g} \cdot \Gamma_{e n g} \\
& =P_{i g}-P_{f}
\end{aligned}
$$

Equations (8) and (10) together directly lead to:

$$
P_{\text {fuel }}=\frac{1}{\eta_{f i}} \cdot\left(P_{b}+P_{f}\right)
$$

The friction power is calculated by multiplying the friction mean effective pressure (considered as a linear function of engine speed) with the cylinder volume, $V_{d}$ :

$$
P_{f}=\left(f+f_{p} \cdot w_{\text {eng }}\right) \cdot \frac{V_{d}}{2} \times w_{\text {eng }}
$$

where $f$ and $f_{p}$ are linear coefficients. Factor 2 comes from the four-stroke engine. Thus the fuel mass flow rate can be easily evaluated as follow:

$$
\dot{m}_{f u e l}=\frac{P_{b}+\left(f+f_{p} \cdot w_{e n g}\right) \cdot \frac{V_{d} \cdot w_{e n g}}{2}}{\eta_{f i} \cdot L H V}
$$

More details about this model and typical numerical values can be found in [4]. This model allows to describe the vehicle motion and engine behavior on a given cycle. The following section presents an excess fuel consumption model.

\section{Excess fuel consumption model}

In order to take into account the effect of engine temperature on its overall efficiency, an excess fuel consumption model is developed, in which mechanical losses increase with oil viscosity. As a first approach, the fuel indicated efficiency $\eta_{f i}$ is considered independent of the thermal state of the engine.

Assumption is made that (13) gives the fuel consumption at thermal equilibrium (subscript te). For a given value of the brake power $P_{b}$, the excess fuel consumption $\Delta \dot{m}_{f u e l}$ in regard to this equilibrium comes only from variations in the mechanical losses:

$$
\Delta \dot{m}_{f u e l}=\frac{1}{\eta_{f i} \cdot L H V} \cdot \Delta P_{f}
$$

where $\Delta P_{f}$ are variations in the mechanical losses, and are zeros at thermal equilibrium.
Reference [5] and experimental results show that most of mechanical losses are a function of oil viscosity $\nu$ and engine rotational speed $\omega_{e n g}$. In [6] is provided an expression of oil viscosity as a function of its temperature $T_{o}$, called WalterMac Coull equation:

$$
\nu+a=\exp \left(\frac{B}{T_{o}^{n}}\right)
$$

where $a$ is constant and negligible for motor oil, $B$ and $n$ are characteristics of the specified oil and $T_{o}$ is given in Kelvin. The assumption is made that oil viscosity friction losses are a function of $\nu^{x}$, as proposed in [5], where $x$ is a given value dependent on the considered engine part. The variations in the mechanical losses are then assumed to be of the following form:

$$
\Delta P_{f}=P_{f} \cdot K \cdot\left(\exp \left(\frac{C}{T_{o}^{n}}\right)-\exp \left(\frac{C}{T_{o, t e}^{n}}\right)\right)
$$

where $C$ and $n$ are constant values, $T_{o, t e}$ is the thermal equilibrium oil temperature and $K$ is an experimental fitting factor. Reference [5] gives the following experimental values for a $1.8 \mathrm{~L}$ naturally aspired gasoline engine: $C=10^{8}$ and $n=3$.

Using (11) and (14), the mass fuel rate is written as:

$$
\begin{aligned}
\dot{m}_{f u e l} & =\frac{P_{b}+P_{f}+\Delta P_{f}}{\eta_{f i} \cdot L H V} \\
& =\dot{m}_{f u e l, t e}+\Delta \dot{m}_{\text {fuel }}
\end{aligned}
$$

In order to experimentally fit the model, an engine bench cold-start experiment is carried on a $1.2 \mathrm{~L}$ turbocharged direct injection gasoline engine. The thermal equilibrium fuel consumption is directly available, and that allows to free the experiment from the engine model to focus only on excess fuel consumption $\Delta \dot{m}_{\text {fuel }}$. Fig. 1 shows both the real and the modeled fuel consumption, as well as measured temperatures $T_{o}$ and $T_{c}$, that are really close during the experiment. The experimental fitting parameters as presented in (16) are $K=0.5173, C=1.678 \cdot 10^{7}$ and $n=2.8$.

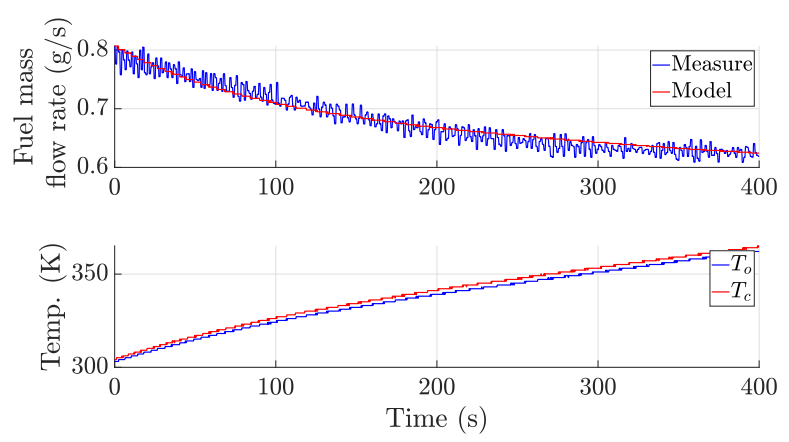

Fig. 1. Cold-start experiment: fuel consumption (upper) and temperatures (lower) $T_{o}$ (blue) and $T_{c}$ (red)

\section{Thermal model}

In [7], a detailed thermal model of an engine cooling circuit is proposed. It is made of three actuators (namely a coolant pump, a bypass valve and a fan), along with an engine block thermal model and a radiator (see Fig. 2 and 
Fig. 3). This model is slightly adjusted to the needs of this paper. Four temperatures are calculated, namely the cylinder temperature $T_{c y l}$, the engine block temperature $T_{e b}$, the outof-the-engine-block coolant temperature $T_{c}$ and the out-ofthe-radiator coolant temperature $T_{r}$. The model assumes no time delays due to the pipes in the circuit, as well as no radiation-based heat exchanges. Moreover, no thermal inertia is considered for the radiator mass. The following heat balances are used to calculate the temperatures:

$$
\begin{aligned}
& m_{c y l} \cdot C_{p, c y l} \cdot \frac{\mathrm{d} T_{c y l}}{\mathrm{~d} t}=Q_{c y l}-Q_{c y l, c o o l} \\
& m_{e b} \cdot C_{p, e b} \cdot \frac{\mathrm{d} T_{e b}}{\mathrm{~d} t}=Q_{c o o l, e b}-Q_{e b, a m b} \\
& m_{c} \cdot C_{p, c} \cdot \frac{\mathrm{d} T_{c}}{\mathrm{~d} t}=Q_{c y l, c o o l}+Q_{f l o w, e b}-Q_{c o o l, e b} \\
& m_{r} \cdot C_{p, r} \cdot \frac{\mathrm{d} T_{r}}{\mathrm{~d} t}=Q_{\text {flow }, \text { rad }}-Q_{\text {rad }, a m b}
\end{aligned}
$$

In (19)-(22), $Q_{c y l}$ are the heat losses from cylinders, i.e. the heat input in the system, that depends only on the engine speed and torque. $Q_{c y l, c o o l}$ and $Q_{c o o l, e b}$ are the heat transfers from cylinders to coolant and from coolant to engine block respectively, $Q_{\text {flow,eb }}$ and $Q_{\text {flow,rad }}$ are the enthalpy fluxes due to the coolant mass flow in the engine block and in the radiator respectively, and $Q_{e b, a m b}$ and $Q_{r a d, a m b}$ are the heat fluxes from the engine block and the radiator respectively to the ambient. $m_{c y l}, m_{e b}, m_{c}$ and $m_{r}$ are, respectively, the cylinder mass, the engine block mass, the coolant mass in the engine and the coolant mass in the radiator. $C_{p, c y l}, C_{p, e b}, C_{p, c}$ and $C_{p, c}$ are, respectively, the heat capacities of the cylinder, the engine block, the coolant in the engine and the coolant in the radiator.

This 4-states, 3-control variables model has to be simplified in order to be used in the optimization process. Section II-E deals with such a reduction of states and control variables.

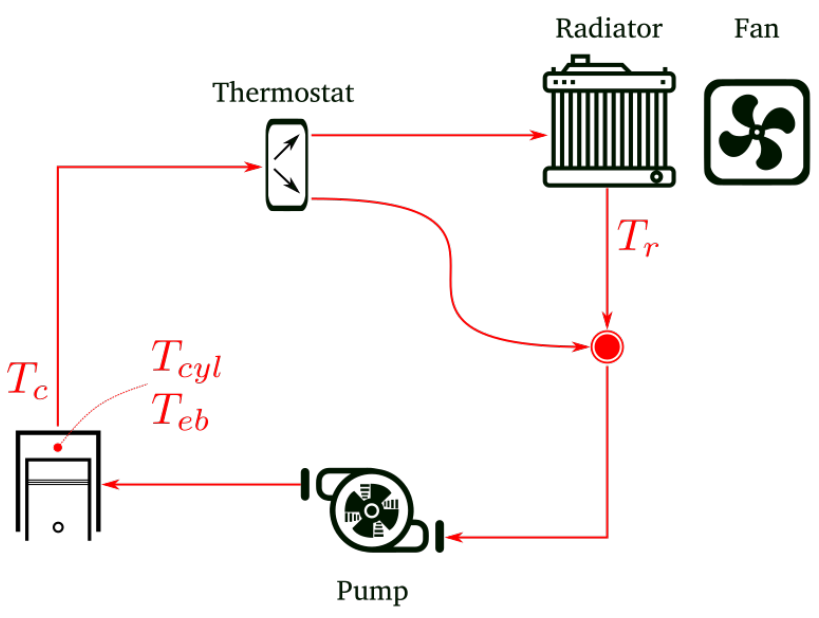

Fig. 2. General structure of the complete model

\section{E. Simplified thermal model}

In order to reduce the model complexity, both number of states and control variables have to be lowered. Due to the closed loop of coolant, temperatures $T_{c}$ and $T_{r}$ at time $t$ will influence each other at time $t+\Delta t$. In order to keep accurate

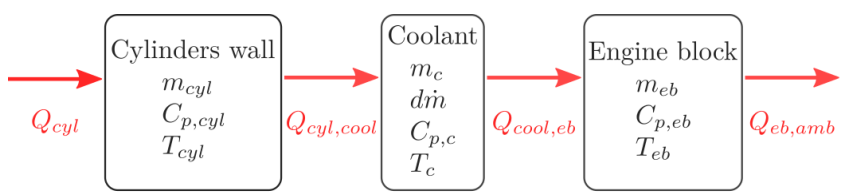

Fig. 3. Engine block representation - complete model

dynamics in the model, both temperatures $T_{c}$ and $T_{r}$ must be kept. However, the engine block model can be simplified by considering direct heat rejections from the cylinder in the coolant, itself exchanging with the ambient. Both cylinders wall and engine block wall, together with their respective temperatures and thermal inertias, are then removed from the model, as shown in Fig. 5. Coolant heat capacities $C_{p, c}$ and $C_{p, r}$ are taken constant, independent from the temperature. Power characteristic curves of the actuators are quadratic, which is of importance for optimization.

Considering the near-zero power consumption of the thermostat, it must be fully open before starting to increase fan speed or pump flow. Thereby, the thermostat is removed from the model. These different assumptions and simplifications lead to a 2-states 2-control variables cooling system model, presented and used in [8]. Fig. 4 shows the model simplified. The related equations are:

$$
\begin{aligned}
& m_{c} \cdot C_{p, c} \cdot \frac{\mathrm{d} T_{c}}{\mathrm{~d} t}=Q_{c y l}+Q_{\text {flow }, e b}-Q_{\text {cool }, a m b} \\
& m_{r} \cdot C_{p, r} \cdot \frac{\mathrm{d} T_{r}}{\mathrm{~d} t}=Q_{\text {flow }, \text { rad }}-Q_{\text {rad }, a m b}
\end{aligned}
$$

where $Q_{\text {cool,amb }}$ is the heat rejection from the coolant to the ambient directly. Replacing heat fluxes by their detailed expression in (23) and (24) leads to:

$$
\begin{aligned}
m_{c} \cdot C_{p, c} \cdot \frac{\mathrm{d} T_{c}}{\mathrm{~d} t}=Q_{c y l} & +d \dot{m} \cdot C_{p} \cdot\left(T_{r}-T_{c}\right) \\
& -H S_{c, a} \cdot\left(T_{c}-T_{a m b}\right)
\end{aligned}
$$

and

$$
\begin{aligned}
m_{r} \cdot C_{p, r} \cdot \frac{\mathrm{d} T_{r}}{\mathrm{~d} t} & =d \dot{m} \cdot C_{p} \cdot\left(T_{c}-T_{r}\right) \\
& -H S_{r d} \cdot\left(T_{r}-T_{a m b}\right)
\end{aligned}
$$

where $d \dot{m}$ is the coolant flow in the circuit, $T_{a m b}$ is the ambient temperature, $H S_{c, a}$ is the heat transfer coefficient between the engine's coolant and the ambient, and $H S_{r d}$ is the heat transfer coefficient between the radiator and the ambient. $H S_{r d}$ depends on the coolant flow $d \dot{m}$, on the fan speed $\omega_{f a n}$ and on the vehicle speed $v . Q_{c y l}$ is obtained experimentally with engine bench measurements.

The main behavior difference between complete and simple model is the loss of temperature dynamics within the engine part. This simplified model has to be adjusted and validated by use of experimental data.

In order to take effects of oil viscosity into account (see section II-C), oil temperature $T_{o}$ is assumed to be equal to coolant temperature $T_{c}$, so that the 2-states modeling is not modified. 


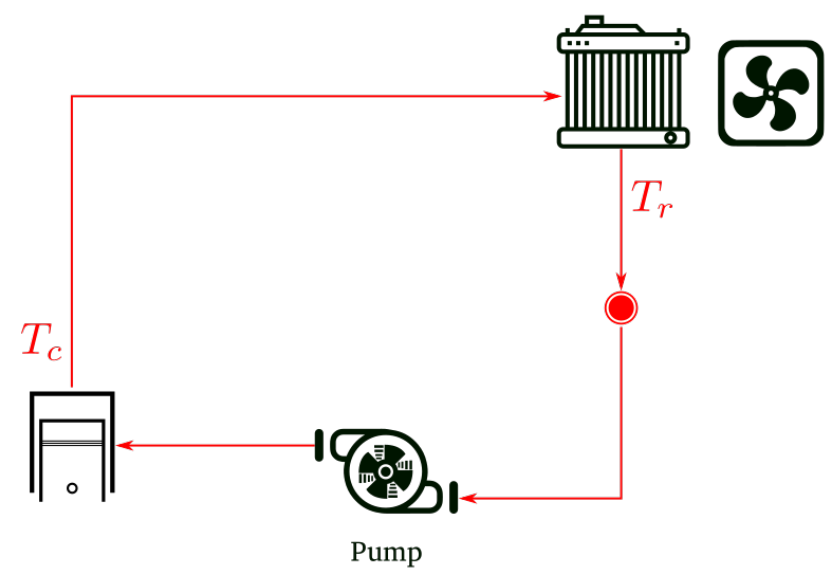

Fig. 4. General structure of the simple model

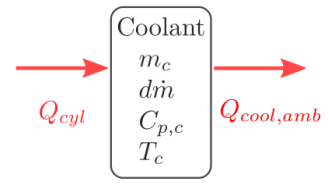

Fig. 5. Engine block representation - simple model

\section{CONTROL AND OPTIMIZATION}

The model presented in section II-E has two states and two control variables. It is used to compare results between non-optimized and optimized controls. This section presents the optimization problem. Fig. 6 shows how the previously presented models interact.

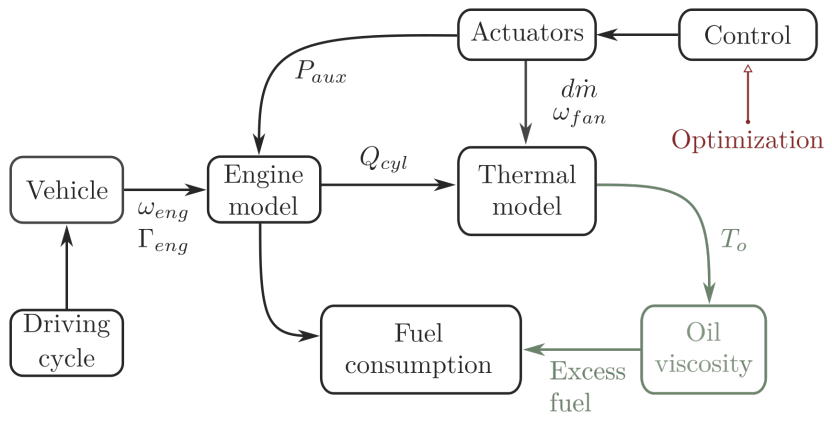

Fig. 6. Interaction of models (oil viscosity: optional)

\section{A. Non-optimal control}

In order to make proper estimation of gains obtained by an optimal control of the actuators, a "non-optimal" control setting has to be chosen. In the option, the water pump is considered mechanically linked to the engine shaft, as it can be found in classical vehicle architecture, so that the coolant flow $d \dot{m}$ is a direct image of the engine speed. Fan speed $\omega_{f a n}$ is enslaved to temperature $T_{c}$ with proportional controller as shown in (27) :

$$
\omega_{f a n}=K_{f a n} \times\left(T_{c}^{*}-T_{c}\right) \times \omega_{f a n, m x}
$$

where $K_{f a n}$ is the proportional gain, $T_{c}^{*}$ is the setpoint temperature and $\omega_{f a n, m x}$ is the maximum fan speed.

\section{B. Criterion}

The optimization criterion is the fuel flow on the cycle :

$$
\begin{aligned}
& \min _{d \dot{m}, \omega_{\text {fan }}} \sum_{i=1}^{n} \dot{m}_{f u e l, i}\left(\Gamma_{\text {eng }, i}, \omega_{\text {eng }, i}\right) \\
& \text { s.t. } \\
& T_{\min } \leq T_{c}, T_{r} \leq T_{\max }
\end{aligned}
$$

where $\dot{m}_{f u e l}$ is the fuel flow, $\omega_{e n g}$ is the engine speed and $\Gamma_{e n g}$ the engine torque. Subscript $i$ relates to the time instant. Both temperatures $T_{c}$ and $T_{r}$ are constrained between temperatures $T_{\min }$ and $T_{\max }$.

\section{Dynamic programing}

Dynamic programming is used to find the optimal solution. It is a well-known algorithm, presented for instance in [9], that provides global optimal solution on a given cycle. Matlab function $d p m$, presented in [10], is used for this purpose. The 2-states 2-control variables model previously described and the optimization criterion are provided to the function, as well as specified limits for states and control grids. As explained in [11], state-space and control-space discretization plays an important part in $\mathrm{dpm}$. In order to find a correct compromise between calculation time and solution accuracy, a parametric study has been carried out, and a discretization of 10 values for both pump and fan control, as well as a $1^{\circ} \mathrm{C}$ step on temperatures has been chosen.

\section{Results}

\section{A. Vehicle and cycle presentation}

The considered vehicle is a semi-trailer truck from Renault Trucks group, whose main characteristics are listed in Table I.

TABLE I. VEHIClE PARAMETERS

\begin{tabular}{|l|l|}
\hline Vehicle weight & $33^{\prime} 000 \mathrm{~kg}$ \\
Internal Combustion Engine & $13 \mathrm{~L}$ Diesel engine \\
& EURO VI compliant \\
ICE power & $360 \mathrm{~kW} @ 1400 \mathrm{rpm}$ \\
Gearbox & 12 speed automated gearbox \\
\hline
\end{tabular}

The driving cycle on which the optimization is performed is the LCG cycle, a $204 \mathrm{~km}$ French highway truck-oriented cycle, presented for instance in [12]. Speed and slope on the cycle are presented in Fig. 7.

\section{B. Non-optimal solution}

Fig. 8 and 9 show evolution of $Q_{c y l}, T_{c}, T_{r}, d \dot{m}$ and $\omega_{\text {fan }}$ on the cycle for the non-optimized solution. As stated previously, the cooling water pump is not controlled, which explains its behavior. Since the fan only reacts to temperature through a proportional controller, there is no sign of anticipation in cooling on the cycle, and coolant radiator temperature $T_{r}$ strongly decreases every times $Q_{c y l}$ increases, since $\omega_{\text {fan }}$ increases as an immediate reaction. Table II gives the numerical global results of the non-optimized solution. 

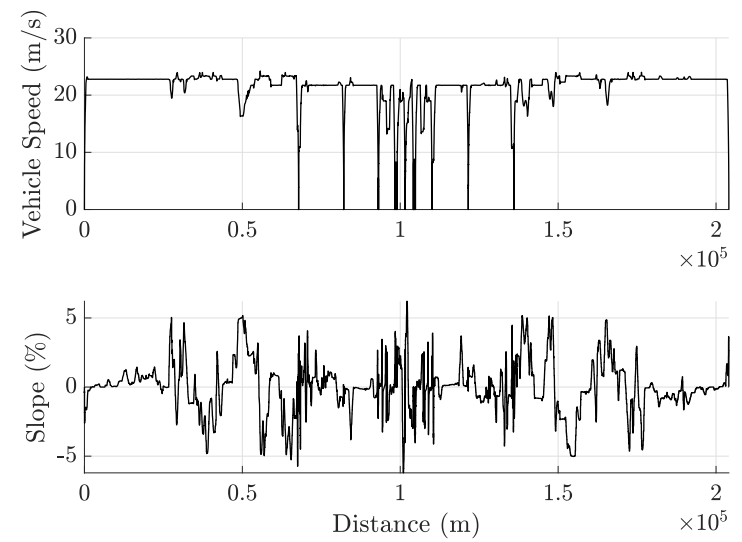

Fig. 7. Speed and slope of LCG cycle

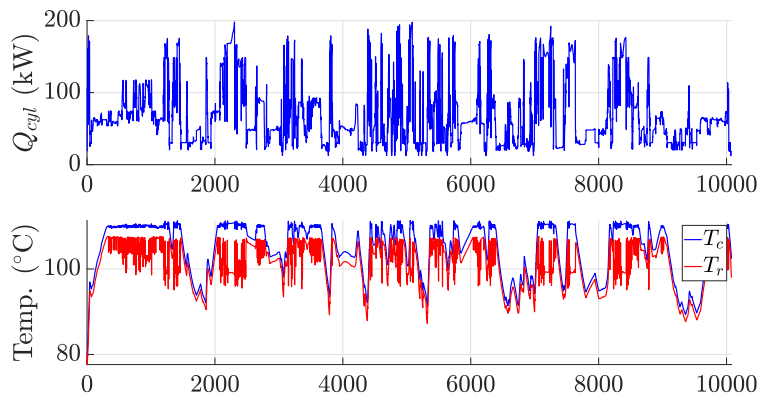

Fig. 8. Non-optimized solution: Heat rejections $Q_{c y l}$ (upper) and temperatures (lower) $T_{c}$ (blue) and $T_{r}$ (orange)
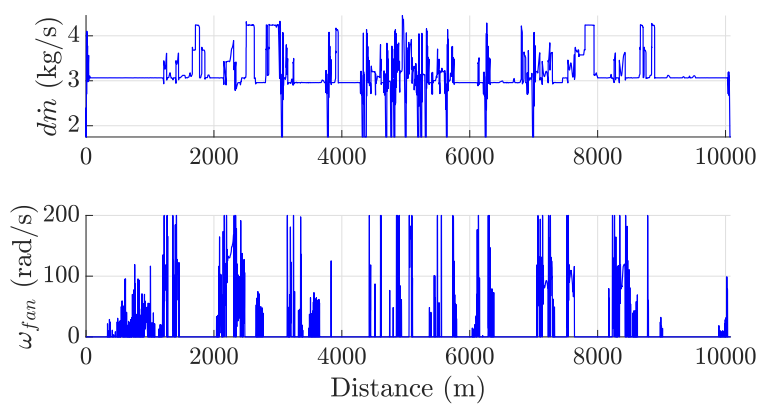

Fig. 9. Non-optimized solution: coolant mass flow $d \dot{m}$ (upper) and fan speed $\omega_{\text {fan }}$ (lower)

\section{Optimal solution without oil temperature consideration}

Fig. 10 and 11 show evolution of $Q_{c y l}, T_{c}, T_{r}, d \dot{m}$ and $\omega_{f a n}$ on the cycle for the optimized solution. The main differences with the non-optimized solution are the pump controllability and the anticipating behavior of actuators. Due to the quadratic characteristic power curves of the pump and the fan, strong heat rejection peaks are anticipated by the cooling system: temperatures $T_{c}$ ant $T_{r}$ are decreasing before the peaks, in order to make the most natural cooling by working at low powers. Temperatures are constrained between ambient temperature and $110^{\circ} \mathrm{C}$, as presented in (29). For this reason, when not anticipating, the system keeps $T_{c}$ as high as possible, since it then reduces the actuators power consumption.
Table II gives the numerical results of the optimized solution and the comparative results of consumption, with respect to the non-optimized solution.

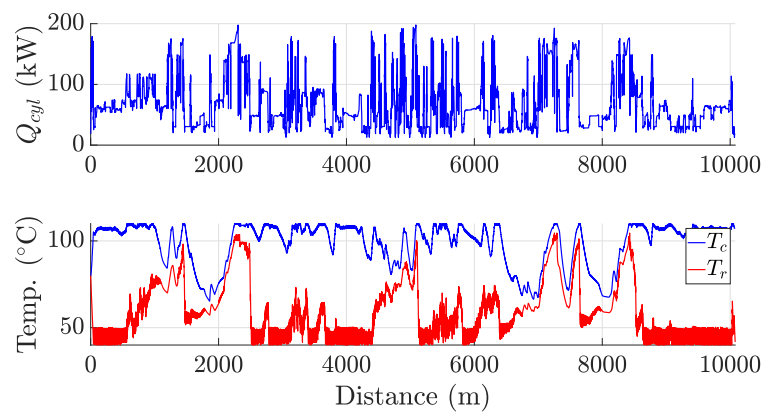

Fig. 10. Optimized solution: Heat rejections $Q_{c y l}$ (upper) and temperatures (lower) $T_{c}$ (blue) and $T_{r}$ (orange)
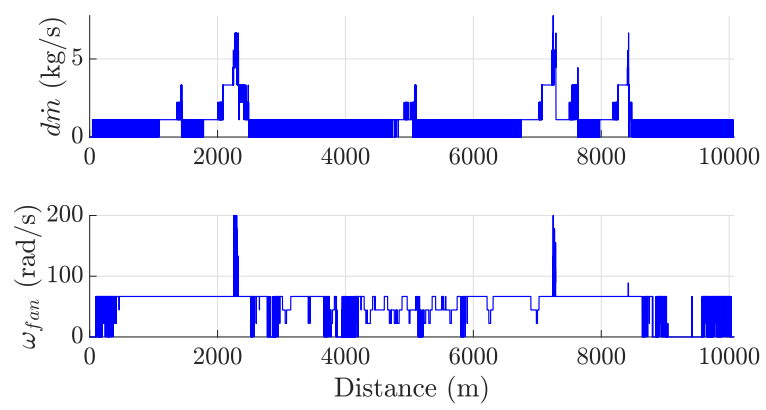

Fig. 11. Optimized solution: coolant mass flow $d \dot{m}$ (upper) and fan speed $\omega_{\text {fan }}$ (lower)

TABLE II. COMPARISON OF THE TWO SOLUTIONS WITHOUT OIL VISCOSITY EFFECT

\begin{tabular}{|l|cc||c|}
\hline & $\begin{array}{c}\text { Non optimized } \\
\text { solution }\end{array}$ & $\begin{array}{c}\text { Optimized } \\
\text { solution }\end{array}$ & Gain (\%) \\
Pump (Wh) & 311 & 49 & 84 \\
Fan (Wh) & 523 & 45 & 91 \\
Total actuators $(\mathrm{Wh})$ & 834 & 94 & 89 \\
\hline & \multicolumn{2}{|c||}{ Total fuel gain } & 0.27 \\
\hline
\end{tabular}

\section{Optimal solution with oil temperature effect on excess fuel consumption}

In this section, the results taking oil viscosity into account are presented. Regarding the non-optimized solution, since the viscosity does not impact the actuators dynamics, only the fuel consumption is changed in comparison to results of section IV-B. However, the behavior of the optimized solution is different when taking oil viscosity effect into account. Fig. 12 and 13 show the results on the cycle in this case. In order to maintain temperature $T_{c}$ between $T_{o, t e}$ the thermal equilibrium oil temperature and the upper constraint $110^{\circ} \mathrm{C}$, the system anticipates less and does not take advantage of natural cooling. Actuators are then used at higher power, which leads to an increase in total actuators energy. However, the fuel consumption gain increases: actuators energy savings have less impact than high oil temperature on total fuel consumption. 

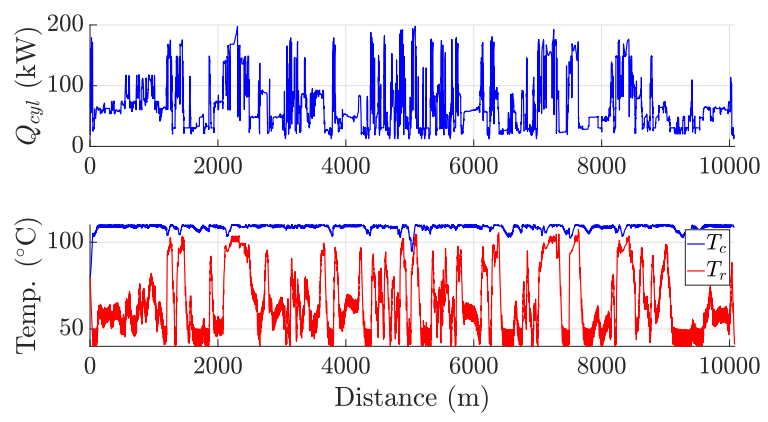

Fig. 12. Optimized solution with oil viscosity effect: Heat rejections $Q_{c y l}$ (upper) and temperatures (lower) $T_{c}$ (blue) and $T_{r}$ (orange)
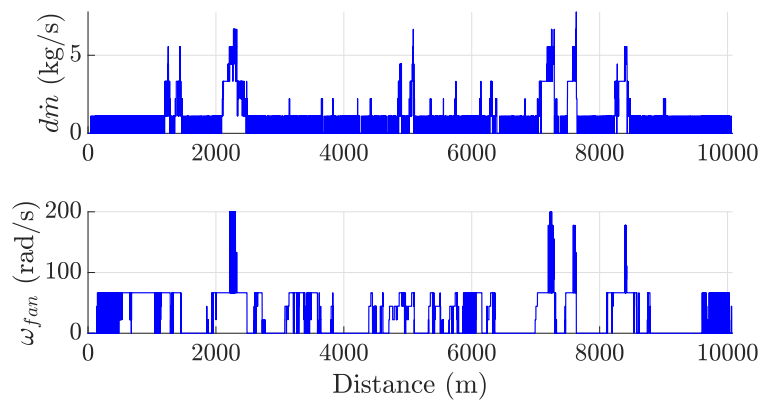

Fig. 13. Optimized solution with oil viscosity effect: coolant mass flow $d \dot{m}$ (upper) and fan speed $\omega_{\text {fan }}$ (lower)

TABLE III. COMPARISON OF THE TWO SOLUTIONS WITH OIL VISCOSITY EFFECT

\begin{tabular}{|l|cc||c|}
\hline & $\begin{array}{c}\text { Non optimized } \\
\text { solution }\end{array}$ & Optimized & Gain (\%) \\
Pump (Wh) & 311 & solution & \\
Fan (Wh) & 523 & 70 & 78 \\
Total actuators $(\mathrm{Wh})$ & 834 & 82 & 84 \\
\hline & \multicolumn{2}{|c||}{ Total fuel gain } & 82 \\
\hline
\end{tabular}

\section{CONCLUSION}

This paper presents a set of energetic-based models used to describe a vehicle behavior, from the mechanical and thermal points of view. Fuel consumption is determined using a simple engine model, and a method to calculate excess fuel consumption due to oil viscosity is proposed. A 2-states 2 -control variables thermal model is also detailed. Dynamic programming algorithm is then used to quantify the potential fuel reduction on a given driving cycle. Gains up to $89 \%$ can be reached on actuators energy, which leads to a fuel consumption reduction of $0.27 \%$. An important contribution of this work is the consideration of oil viscosity and its effect on fuel consumption: from the overall fuel consumption point of view, it is more interesting to maintain low oil viscosity than to optimize the actuators consumption only. The effect of modeling and optimization parameters has not yet been properly quantify, but parameters such as actuators grid size or setpoint temperature $T_{c}^{*}$ might play an important part on optimization results.

\section{REFERENCES}

[1] E. Vinot, J. Scordia, R. Trigui, B. Jeanneret, and F. Badin, "Model simulation, validation and case study of the 2004 ths of toyota prius," International Journal of Vehicle Systems Modelling and Testing, 2008.

[2] J. Scordia, R. Trigui, M. Desbois-Renaudin, B. Jeanneret, and F. Badin, "Global approach for hybrid vehicle optimal control," Journal for Asian Electric Vehicles, 2009.

[3] E. Vinot and R. Trigui, "Optimal energy management of HEVs with hybrid storage system," Energy Conversion and Management, vol. 76, pp. 437-452, 2013.

[4] Z. Asus, D. Chrenko, E. Aglzim, A. Kéromnès, and L. Le Moyne, "Simple method of estimating consumption of internal combustion engine for hybrid application," 2012 IEEE Transportation Electrification Conference and Expo (ITEC), pp. 1-6, June 2012.

[5] J. P. Roumegoux, "Logiciel de simulation SIMULCO Version 1.1. Fonctionnalités nouvelles et Modélisation du départ à froid," Rapport LEN 9818, INRETS, Tech. Rep., May 1998.

[6] J. Ayel, "Lubrifiants - propriétés et caractéristiques," in Génie mécanique | Frottement, usure et lubrification. Techniques de l'Ingénieur, 1996.

[7] L. Guzzella and C. Onder, Introduction to Modeling and Control of Internal Combustion Engine Systems, ser. Springer Nature Book Archives Millennium. Springer, 2004.

[8] M. Khodabakhshian, L. Feng, and J. Wikander, "Predictive control of the engine cooling system for fuel efficiency improvement," 2014 IEEE International Conference on Automation Science and Engineering (CASE), pp. 61-66, Aug 2014.

[9] R. Bellman, Dynamic Programming. Princeton, NJ, USA: Princeton University Press, 2010.

[10] O. Sundström and L. Guzzella, "A generic dynamic programming matlab function," 2009 IEEE Control Applications, (CCA) \& Intelligent Control, (ISIC), pp. 1625-1630, 2009.

[11] O. Sundström, D. Ambühl, and L. Guzzella, "On implementation of dynamic programming for optimal control problems with final state constraints," Oil \& Gas Science and Technology-Revue de l'Institut Français du Pétrole, vol. 65, no. 1, pp. 91-102, 2010.

[12] F. Galuppo, T. Reiche, V. Lemort, P. Dufour, M. Nadri, and X. Huin, "Waste heat recovery (whr) assessment in complete truck simulation environment," Proceedings of the 2018 SIA POWERTRAIN conference, May 2018 